BLUM, L.E.B.; AMARANTE, C.V.T.; GÜTTLER, G.; MACEDO, A. F.; KOTHE, D.; SIMMLER, A.; PRADO, G.; GUIMARÃES, L. Produção de moranga e pepino em solo com incorporação de cama aviária e casca de pinus. Horticultura Brasileira, Brasília, v. 21, n.4, p. 627-631, outubro/dezembro 2003.

\title{
Produção de moranga e pepino em solo com incorporação de cama aviária e casca de pinus
}

\author{
Luiz Eduardo B. Blum ${ }^{1}$; Cassandro V.T. do Amarante ${ }^{2}$; Germano Güttler²; Alexandre F. de Macedo²; \\ Daniel Marcelo Kothe ${ }^{2}$; Arno Otmar Simmler²; Giuliani do Prado $^{2}$; Letícia Simone Guimarães ${ }^{2}$ \\ ${ }^{1}$ UnB, Depto. Fitopatologia, 70919-970 Brasília-DF; E-mail: luizblum@unb.br; ²UDESC-CAV, C. Postal 281, 88502-970 Lages-SC; E- \\ mail: amarante@cav.udesc.br
}

\section{RESUMO}

A cama aviária e a casca de pinus (Pinus taeda) são subprodutos de empresas avícolas e florestais que podem ser utilizados na melhoria da fertilidade e das propriedades físicas e químicas do solo. As morangas 'Tetsukabuto' (Cucurbita maxima x C. moschata) e 'Exposição' (Cucurbita maxima) e o pepino 'Caipira' (Cucumis sativus) estão entre as cucurbitáceas mais cultivadas em Santa Catarina. Avaliou-se os efeitos de doses ( 0 a 50 g. kg-1 de solo) de cama aviária $(2,82 \% \mathrm{~N} ; 2,53 \% \mathrm{P} ; 1,2 \% \mathrm{~K} ; 2,5 \% \mathrm{Ca} ; 0,5 \% \mathrm{Mg})$ e da casca de pinus $(0,30 \% \mathrm{~N} ; 0,10 \% \mathrm{P} ; 0,12 \% \mathrm{~K} ; 0,21 \% \mathrm{Ca} ; 0,03 \%$ $\mathrm{Mg}$ ), incorporadas ao solo, no desenvolvimento de plantas e na produção de moranga e pepino. Os experimentos foram delineados em blocos ao acaso, desenvolvidos em casa de vegetação e no campo, e, dependendo do experimento, possuíam tratamentos variando de quatro a cinco, e, repetições de quatro a oito. Em casa de vegetação, doses de cama aviária de até $30 \mathrm{~g} \mathrm{~kg}^{-1}$ de solo (correspondendo a $\sim 3$ $\left.\mathrm{kg} \mathrm{m}^{-2}\right)$ aumentaram as plantas emergentes $(\sim 15 \%$ a $50 \%)$ e a massa da matéria fresca ( $\sim 90 \%$ a $200 \%$ ) de plantas de moranga 'Exposição' e de pepino 'Caipira'. O pH e os conteúdos de Ca, K, Mg, Mn, $\mathrm{N}, \mathrm{P}$ e $\mathrm{Zn}$ do solo aumentaram com o incremento das doses de cama aviária. O incremento nas doses de casca de pinus diminuiu ( $27 \%)$ os níveis de nitrogênio mineral do solo. Nos experimentos de campo, a incorporação de cama aviária e casca de pinus aumentou a emergência ( $15 \%$ ) de plântulas de pepino. A produção de frutos de moranga 'Tetsukabuto' e de pepino 'Caipira' aumentou ( $120 \%)$ nos tratamentos com cama aviária, na dose de $30 \mathrm{~g} \mathrm{~kg}^{-1}$ (correspondendo $\mathrm{a} \sim 3 \mathrm{~kg} \mathrm{~m}^{-2}$ ).

Palavras-chave: Cucurbita spp., Cucumis sativus, resíduos orgânicos, fertilização.

\begin{abstract}
Production of squash and cucumber in soil amended with poultry manure and pine bark

Poultry manure and pine bark (Pinus taeda) are by-products readily available in the State of Santa Catarina, Brazil. These byproducts can be used as soil amendments to improve soil fertility and soil physical and chemical properties. Inter-specific hybrid squash cv. 'Tetsukabuto' (Cucurbita maxima x C. moschata), squash cv. 'Exposição' (Cucurbita maxima), and cucumber cv 'Caipira' (Cucumis sativus) are three of the most cultivated cucurbits in Santa Catarina. The effect of rates ( 0 to 50 g. $\mathrm{kg}^{-1}$ of soil) of poultry manure $(2.82 \% \mathrm{~N} ; 2.53 \% \mathrm{P} ; 1.2 \% \mathrm{~K} ; 2.5 \% \mathrm{Ca} ; 0.5 \% \mathrm{Mg})$ and pine bark $(0.30 \% \mathrm{~N} ; 0.10 \% \mathrm{P} ; 0.12 \% \mathrm{~K} ; 0.21 \% \mathrm{Ca} ; 0.03 \% \mathrm{Mg})$ incorporated into the soil, was evaluated on plant growth and yield of squash and cucumber. The greenhouse and field tests were conducted in a completely randomized block design with four or five treatments and four to eight replications. In greenhouse, poultry manure at doses of $30 \mathrm{~g} \mathrm{~kg}^{-1}$ of soil (corresponding to $\sim 3 \mathrm{~kg} \cdot \mathrm{m}^{-2}$ ) increased the number ( $\sim 15-50 \%)$ and the fresh mass ( $\sim 90-200 \%)$ of emerging plants of squash cv. 'Exposição' and cucumber cv. 'Caipira'. Soil pH and soil concentration of $\mathrm{Ca}, \mathrm{K}, \mathrm{Mg}, \mathrm{Mn}, \mathrm{N}, \mathrm{P}$, and $\mathrm{Zn}$ increased with increasing poultry manure doses. The increase of pine bark dose applied to the soil reduced $(\sim 27 \%)$ the levels of mineral nitrogen. In field trials, poultry manure and pine bark increased the emergence $(\sim 15 \%)$ of cucumber seedlings. The fruit yield of squash cv. 'Tetsukabuto' and cucumber cv. 'Caipira' increased ( 120\%) with the incorporation of poultry manure to the soil at the doses of $30 \mathrm{~g}$ $\mathrm{kg}^{-1}$ (corresponding to $\sim 3 \mathrm{~kg} \mathrm{~m}^{-2}$ ).
\end{abstract}

Keywords: Cucurbita spp., Cucumis sativus, organic residues, fertilization.

(Recebido para publicação em 27 de junho de 2002 e aceito em 12 de agosto de 2003)

\begin{abstract}
$\mathrm{A}$ moranga híbrida 'Tetsukabuto' (Cucurbita maxima x C. moschata), a moranga 'Exposição' (Cucurbita maxima) e o pepino 'Caipira' (Cucumis sativus) são culturas importantes na geração de renda em propriedades agrícolas do estado de Santa Catarina. Trabalhos têm sido realizados para avaliar os efeitos da época, espaçamento e sistema de cultivo e de fertilizantes na produção de cucurbitáceas (Amarante \& Macedo, 2000; Macedo et al., 1999). Todavia, poucos estudos foram conduzidos para
\end{abstract}

avaliar os efeitos da adição de resíduos orgânicos ao solo no desenvolvimento e rendimento destas culturas.

A cama aviária possui compostos ricos em nitrogênio, que auxiliam no aumento da produção de algumas culturas (Scherer, 1995; Zárate et al., 1997) e na redução de fitopatógenos que sobrevivem no solo (Blum et al., 1999). Além de nitrogênio (2,6-3,0\% de $\mathrm{N})$, a cama aviária possui fósforo $(3,9-4,5 \%$ de P) e potássio (1,0-3,0\% de K) em níveis elevados (Ernani, 1984; Gianello \& Ernani, 1983; Miele \& Milan, 1983;
Kothe et al., 1999; Scherer, 1995). Os teores de N, P, K, Ca e Mg podem variar ligeiramente, dependendo da origem da cama de aviário (frangos de corte ou galinhas poedeiras) e do número de camadas de maravalha (Gianello \& Ernani, 1983; Miele \& Milan, 1983; Scherer, 1995). A adição ao solo de cama aviária aumenta o $\mathrm{pH}$ e diminui o teor de alumínio trocável, e, portanto, diminui os efeitos tóxicos deste íon para as plantas (Ernani \& Gianello, 1983).

A casca seca de pinus (Pinus taeda), subproduto da indústria de papel e ce- 
lulose, não possui propriedades fertilizantes marcantes devido a sua baixa concentração de nutrientes $(0,22 \%$ de $\mathrm{N}$, $0,02 \%$ de $\mathrm{P}$ e $0,08-0,11 \%$ de K) (Blum, 1998; Simmler et al., 1999), sendo normalmente descartada ou queimada. Todavia, se esta casca é seca, moída e incorporada ao solo pode melhorar as suas propriedades físicas (textura e drenagem) (Odneal \& Kaps, 1990).

Considerando a boa disponibilidade de cama aviária e de casca de pinus em Santa Catarina, avaliou-se o efeito destes materiais, incorporados ao solo, no desenvolvimento de cucurbitáceas em casa de vegetação, e na produtividade da moranga 'Tetsukabuto' e do pepino 'Caipira' em condições de campo.

\section{MATERIAL E MÉTODOS}

A cama aviária (fezes e resíduos da produção de frangos de corte) e a casca de pinus (Pinus taeda) foram secas em galpão ventilado à temperatura ambiente $\left(15-30^{\circ} \mathrm{C}\right)$ e armazenadas em sacos de polietileno $(20 \mathrm{~kg})$. A casca de pinus, após a secagem, foi moída em moinho triturador de material vegetal, obtendose partículas com 2-3 mm de tamanho. $\mathrm{Na}$ análise de composição elementar, determinada pelos métodos descritos por Tedesco et al. (1995), a cama aviária, apresentou valores de $2,82 \%$ de $\mathrm{N}$, $2,53 \%$ de $\mathrm{P}, 1,2 \%$ de $\mathrm{K}, 2,5 \%$ de $\mathrm{Ca}$ e $0,5 \% \mathrm{Mg}$, enquanto a casca de pinus apresentou valores de $0,30 \%$ de $\mathrm{N}$, $0,10 \%$ de $\mathrm{P}, 0,12 \%$ de $\mathrm{K}, 0,21 \%$ de $\mathrm{Ca}$ e $0,03 \%$ de $\mathrm{Mg}$.

\section{Experimentos em casa de vegetação}

Os experimentos em casa de vegetação, realizados com moranga 'Exposição' e pepino 'Caipira', foram conduzidos no Centro de Ciências Agroveterinárias (CAV) da Universidade do Estado de Santa Catarina, em Lages, de 12/98 a 03/99.

O solo utilizado (CAMBISSOLO HÚMICO Alumínico) foi peneirado para tamanho de partícula de $5 \mathrm{~mm} \mathrm{e}$ acondicionado em sacos pretos de polietileno (2 L). A cama aviária e a casca de pinus foram incorporadas ao solo nas doses de $0 ; 10 ; 30$ e $50 \mathrm{~g} \mathrm{~kg}^{-1}$ de solo (correspondendo, em condições de campo, a doses aproximadas de $0 ; 1 ; 3$ e $5 \mathrm{~kg} \mathrm{~m}^{-2}$ ). Os experimentos com cama aviária e com casca de pinus foram delineados em blocos ao acaso, onde foram utilizadas oito e sete repetições por tratamento, respectivamente. A cada três dias, até a semeadura, as unidades experimentais foram irrigadas até a capacidade de campo.

Três semanas após a incorporação da cama aviária e da casca de pinus, semeou-se cinco sementes de moranga ou dez sementes de pepino por saco de polietileno. A irrigação das unidades experimentais foi efetuada diariamente. Trinta dias após o início da germinação, avaliou-se o número de plantas emergentes e a massa da matéria fresca das plantas por unidade experimental.

No mesmo substrato (solo+cama aviária e solo+casca de pinus) de cada experimento, após o primeiro cultivo (moranga e pepino), foram efetuadas mais três semeaduras de moranga e de pepino conforme descrito anteriormente, um dia após a coleta de dados das semeaduras anteriores. Os dados (médias das quatro semeaduras) foram submetidos à análise de regressão polinomial para avaliar os efeitos dos tratamentos sobre o número e a matéria fresca das plantas.

Após o quarto cultivo, correspondendo a cento e cinqüenta dias após à incorporação de cama aviária e casca de pinus ao solo, os teores residuais de macronutrientes e micronutrientes e o $\mathrm{pH}$ do solo foram determinados através dos procedimentos e métodos propostos por Tedesco et al. (1995). Os dados obtidos foram submetidos à análise de regressão linear e polinomial para avaliar os efeitos dos tratamentos sobre as características químicas do solo.

\section{Experimentos de campo}

Os experimentos de campo, com moranga híbrida 'Tetsukabuto' e pepino 'Caipira', foram realizados nos municípios catarinenses de Bocaina do Sul e Palmeira, respectivamente. Em ambas localidades utilizou-se um CAMBISSOLO HÚMICO Alumínico sem correção de $\mathrm{pH}$, submetido ao preparo convencional, com uma aração e duas gradagens. Os adubos orgânicos foram aplicados e incorporados após a aração. Nestes experimentos foi incluído, além dos tratamentos com cama aviária e casca de pinus, tratamento com o fungicida metalaxyl $\left(80 \mathrm{~g}\right.$ i.a. $\left.\mathrm{kg}^{-1}\right)+$ mancozeb (640 g i.a. $\left.\mathrm{kg}^{-1}\right)$, já que a área experimental apresentava histórico de infestação com Phytophthora capsici, servindo como padrões de controle em caso de eventual epidemia ocasionada pelo fungo. Avaliou-se a germinação (\%), o número de frutos, o peso médio dos frutos e a produtividade média. Foi avaliado também o $\mathrm{pH}$ do solo nos diferentes tratamentos aos 120 dias após a semeadura.

A moranga 'Tetsukabuto' foi semeada em 31/11/1998, após a incorporação da cama aviária ou da casca de pinus, realizada em 26/11/1998, no espaçamento $1 \times 3 \mathrm{~m}$. A dose incorporada de cama aviária ou de casca de pinus foi de $30 \mathrm{~g} \mathrm{~kg}^{-1}$ (correspondendo a aproximadamente $3 \mathrm{~kg} \mathrm{~m}^{-2}$ ). No tratamento fungicida, metalaxyl + mancozeb foi aplicado três vezes (quinzenalmente), a partir do surgimento dos frutos, nas doses de 1,5 e 3,0 $\mathrm{kg}$ (produto comercial) ha $^{-1}$. Foi utilizado o delineamento em blocos ao acaso com cinco tratamentos e oito repetições. Cada bloco foi constituído de 12 plantas, sendo 10 plantas de moranga 'Tetsukabuto' e duas plantas de polinizadora (moranga 'Exposição'). A cama aviária e a casca de pinus foram aplicadas e incorporadas em uma faixa de $2 \mathrm{~m}$ de largura, ao longo da fila de plantio. Em cada cova, foram adicionados $100 \mathrm{~g}$ do fertilizante 5-20-10.

O pepino 'Caipira' foi semeado em 10/1/1999, no espaçamento de $0,5 \times 1 \mathrm{~m}$. A dose incorporada de cama aviária ou de casca de pinus foi de $30 \mathrm{~g} \mathrm{~kg}^{-1}$ (correspondendo a aproximadamente 3 $\mathrm{kg} \mathrm{m}^{-2}$ ). No tratamento fungicida, metalaxil + mancozeb foi aplicado uma vez, após o surgimento dos frutos, na dose de 3,0 kg (produto comercial) ha- ${ }^{-1}$. Foi utilizado o delineamento em blocos ao acaso com quatro tratamentos e quatro repetições. Cada bloco constituiu-se de duas filas de 10 plantas. A cama aviária e a casca de pinus foram aplicadas e incorporadas em uma faixa de 1 $\mathrm{m}$ de largura ao longo da fila de plantio. Nas covas de semeadura foram adicionados $100 \mathrm{~g}$ do fertilizante 5-20-10.

Para avaliação dos dados dos experimentos de campo foi executada a análise de variância $(\mathrm{F} \leq 0,05)$ e para a comparação entre as médias obtidas foi utilizado o teste de Tukey $(\mathrm{P} \leq 0,05)$. 


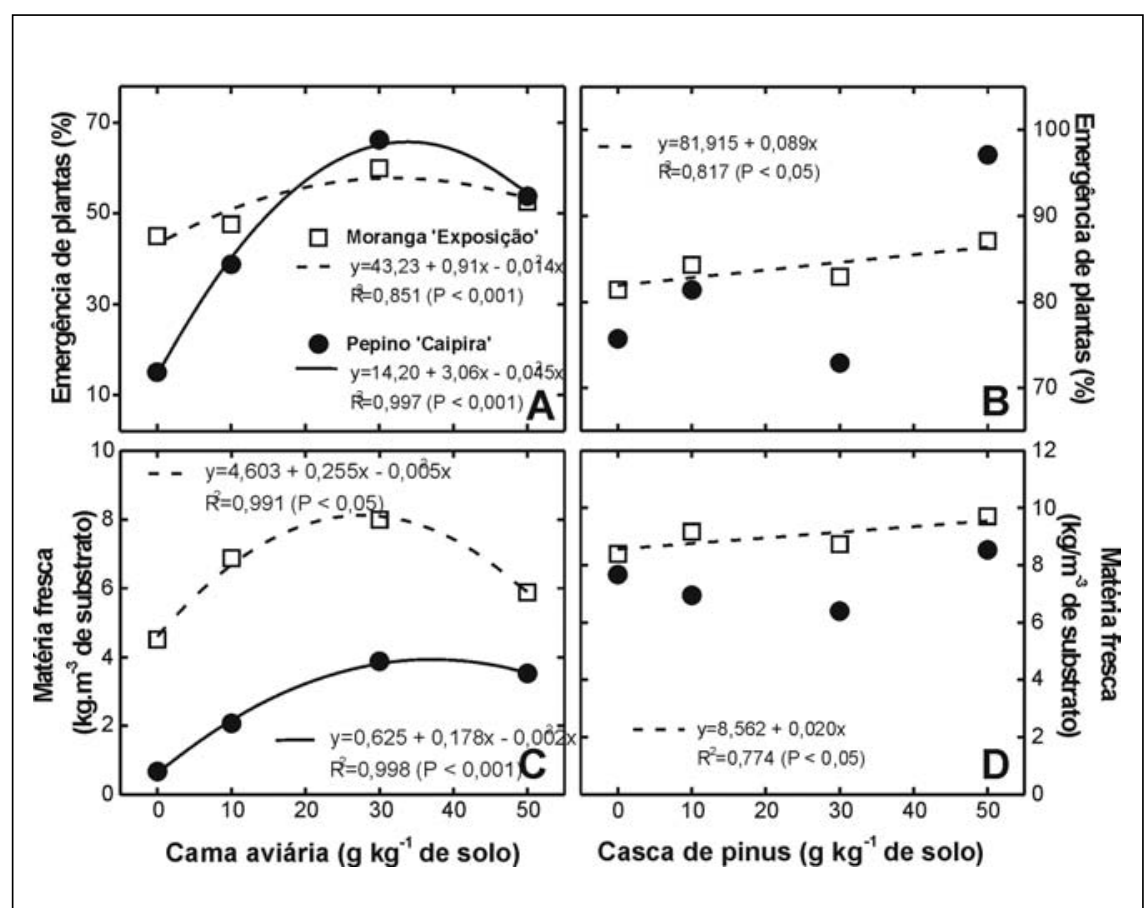

Figura 1. Efeito de doses de cama aviária (A e C) e de casca de pinus (B e D) na porcentagem de emergência e na matéria fresca de plantas de moranga 'Exposição' e pepino 'Caipira' 30 dias após a semeadura, em condições de casa de vegetação. Lages, CAV/UDESC, 1998/99.

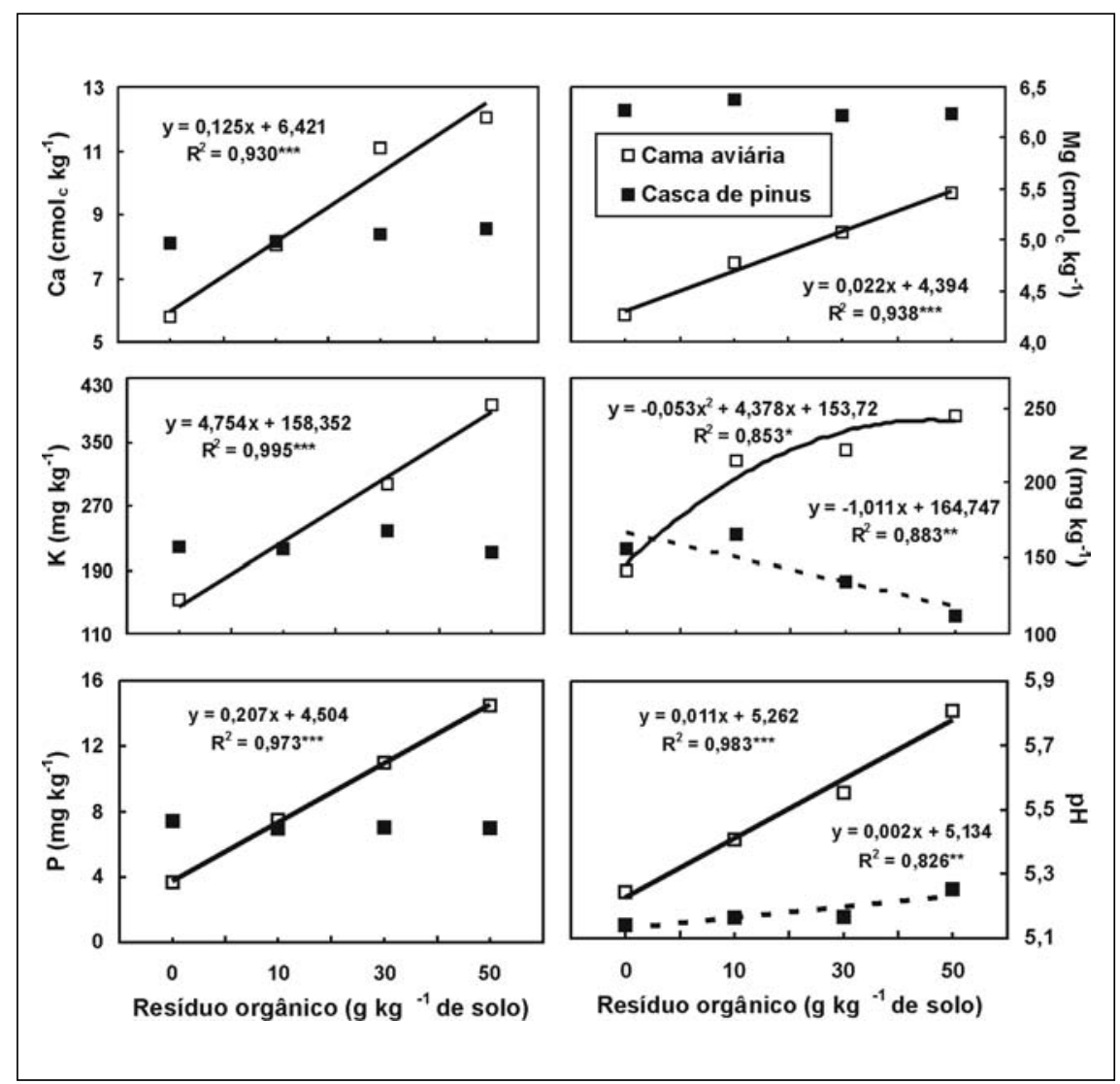

Figura 2. Avaliação residual de macronutrientes no solo, aos 150 dias após a aplicação de cama aviária ou casca de pinus, com quatro cultivos sucessivos de moranga e pepino nesse período $(*, * * \mathrm{e} * * *$ para regressão significativa a 5,1 e $0,1 \%$ de probabilidade, respectivamente). Lages, CAV/UDESC, 1999.

\section{RESULTADOS E DISCUSSÃO}

Plantas de moranga e de pepino foram favorecidas pela adição de cama aviária e casca de pinus ao solo não corrigido. Os resultados dos experimentos em casa de vegetação mostraram que em moranga ‘Exposição' e em pepino ‘Caipira', valores máximos de número e de matéria fresca das plantas foram atingidos em doses de cama aviária entre 28,0 e $35,7 \mathrm{~g} \mathrm{~kg}^{-1}$ (Figura 1). Isto deve estar associado com a melhoria das condições de fertilidade e físicas do solo, e com o aumento na população de organismo benéficos em detrimento da população de organismos patogênicos que sobrevivem no solo (Tsao \& Oster, 1981). Na dose de $50 \mathrm{~g} \mathrm{~kg}^{-1}\left(5 \mathrm{~kg} \mathrm{~m}^{-2}\right)$ houve uma diminuição no número e na matéria fresca das plantas, provavelmente associado ao aumento na concentração salina do solo (Gianello \& Ernani, 1983). A baixa porcentagem de plantas nas doses menores de cama aviária foi ocasionada pela ação de fitopatógenos autóctones, principalmente Phytophthora capsici e Rhizoctonia solani, que foram isolados de plantas afetadas e identificados, conforme a literatura pertinente (Ho, 1981; Erwin et al., 1983; Sneh et al., 1991; Blum et al., 2002).

Os aumentos no número e na massa fresca das plantas com a incorporação de casca de pinus foram menores que os tratamentos que receberam cama aviária (Figura 1). Todavia, em moranga 'Exposição', doses de casca de pinus de até $50 \mathrm{~g} \mathrm{~kg}^{-1}$ aumentaram a percentagem e a massa fresca de plantas por embalagem. A casca de pinus pode melhorar as condições físicas, químicas e biológicas do solo, e assim reduzir a incidência de doenças ocasionadas por patógenos do solo (Blum, 1998).

A contribuição nutricional ao solo advinda da cama aviária foi significativa (Figuras 2 e 3). À exceção do $\mathrm{Cu}$ e do $\mathrm{Fe}$, os níveis residuais (após quatro cultivos consecutivos das plantas no mesmo solo) de diversos macronutrientes (N, P, K e Ca) e micronutrientes ( $\mathrm{Zn}$ e $\mathrm{Mn}$ ) aumentaram com o aumento da dose de cama aviária aplicada ao solo. $\mathrm{O}$ pH aumentou e a concentração do $\mathrm{Al}$ trocável diminuiu com o aumento da quantidade de cama 
Tabela 1. Emergência de plântulas, rendimento e peso médio de frutos em moranga híbrida 'Tetsukabuto' (Bocaina do Sul, SC, 1998/99) e pepino 'Caipira' (Palmeira, SC, 1998/99) cultivados em solo que recebeu 30 t ha $^{-1}$ de cama aviária ou de casca de pinus. Bocaina e Palmeira, CAV/UDESC, 1999.

\begin{tabular}{|c|c|c|c|c|}
\hline \multirow{3}{*}{ Tratamentos } & \multirow{2}{*}{ Emergência (\%) } & \multicolumn{2}{|c|}{ Rendimento } & \multirow{2}{*}{$\begin{array}{l}\text { Peso médio de } \\
\text { frutos }(\mathbf{k g})\end{array}$} \\
\hline & & Frutos ha-1 $^{-1}$ & $\mathrm{t} \mathrm{ha}^{-1}$ & \\
\hline & \multicolumn{4}{|c|}{ Moranga 'Tetsukabuto' } \\
\hline Controle & $65,63 a^{1}$ & $3.190 \mathrm{~b}$ & $6,67 \mathrm{~b}$ & $2,09 a$ \\
\hline Met + Man $1,5^{2}$ & 71,88 a & $3.220 \mathrm{~b}$ & 7,02 b & $2,10 \mathrm{a}$ \\
\hline Met $+\operatorname{Man} 3,0^{3}$ & 69,79 a & $3.130 \mathrm{~b}$ & $6,83 \mathrm{~b}$ & $2,18 a$ \\
\hline Cama aviária & 83,33 a & $6.090 \mathrm{a}$ & $14,49 a$ & $2,39 a$ \\
\hline Casca de pinus & $80,21 \mathrm{a}$ & $3.470 \mathrm{~b}$ & $6,49 \mathrm{~b}$ & $1,84 \mathrm{a}$ \\
\hline C.V. (\%) & 20,48 & 18,37 & 22,60 & 17,27 \\
\hline \multirow[t]{2}{*}{ D.M.S. ${ }^{4}$} & 21,78 & 2.600 & 7,40 & 0,56 \\
\hline & \multicolumn{4}{|c|}{ Pepino 'Caipira' } \\
\hline Controle & $47,50 \mathrm{~b}$ & $95.250 \mathrm{~b}$ & $25,88 b$ & $0,267 a$ \\
\hline Met + Man $3,0^{3}$ & $52,25 \mathrm{~b}$ & $75.500 \mathrm{~b}$ & $20,08 \mathrm{~b}$ & $0,272 a$ \\
\hline Cama aviária & $62,25 \mathrm{a}$ & $178.000 \mathrm{a}$ & $60,18 a$ & $0,343 a$ \\
\hline Casca de pinus & $62,25 \mathrm{a}$ & $76.500 \mathrm{~b}$ & $22,58 \mathrm{~b}$ & $0,295 a$ \\
\hline C.V. $(\%)$ & 13,47 & 23,56 & 33,80 & 16,39 \\
\hline D.M.S. ${ }^{4}$ & 9,90 & 82.500 & 34,05 & 0,103 \\
\hline
\end{tabular}

${ }^{1}$ Médias nas colunas, seguidas pela mesma letra, não diferem significativamente entre si pelo teste de Tukey $(\mathrm{P}<0,05) .{ }^{2}$ Metalaxyl + mancozeb $\left(80+640 \mathrm{~g}\right.$ i.a. $\left.\mathrm{kg}^{-1}\right)$ na dose de $1,5 \mathrm{~kg}$ de produto comercial ha- ${ }^{-1}{ }^{3}$ Metalaxyl + mancozeb $\left(80+640 \mathrm{~g}\right.$ i.a. $\left.\mathrm{kg}^{-1}\right)$ na dose de $3,0 \mathrm{~kg}$ de produto comercial ha ${ }^{-1} .{ }^{4}$ Diferença mínima significativa.

aviária adicionada ao solo, como demonstrado por Ernani \& Gianello (1983). A maior disponibilidade de alguns nutrientes para a planta pode torná-la mais vigorosa e menos sensível à infecção por patógenos (Hoitink et al., 1996). $\mathrm{O}$ aumento nas doses de casca de pinus ocasionou pequeno, mas significativo aumento nos teores residuais de $\mathrm{Zn}, \mathrm{Cu}$ e $\mathrm{Mn}$ (Figura 3) e diminuiu os teores residuais de $\mathrm{N}$ mineral do solo (Figura 2), possivelmente devido à imobilização de $\mathrm{N}$ pelos microrganismos decompositores da matéria orgânica (Kokalis-Burelle \& Rodríguez-Kábana, 1994).

Os experimentos de campo mostraram que tanto casca de pinus como cama aviária melhoraram significativamente a germinação de sementes de pepino 'Caipira', provavelmente pelo aumento na temperatura do solo resultante da decomposição dos resíduos, mas não a germinação de sementes de moranga 'Tetsukabuto' (Tabela 1). Somente os tratamentos com cama aviária melhoraram significativamente o rendimento de frutos em moranga 'Tetsukabuto' e pepino 'Caipira' (Tabela 1). O peso médio dos frutos de moranga 'Tetsukabuto' e

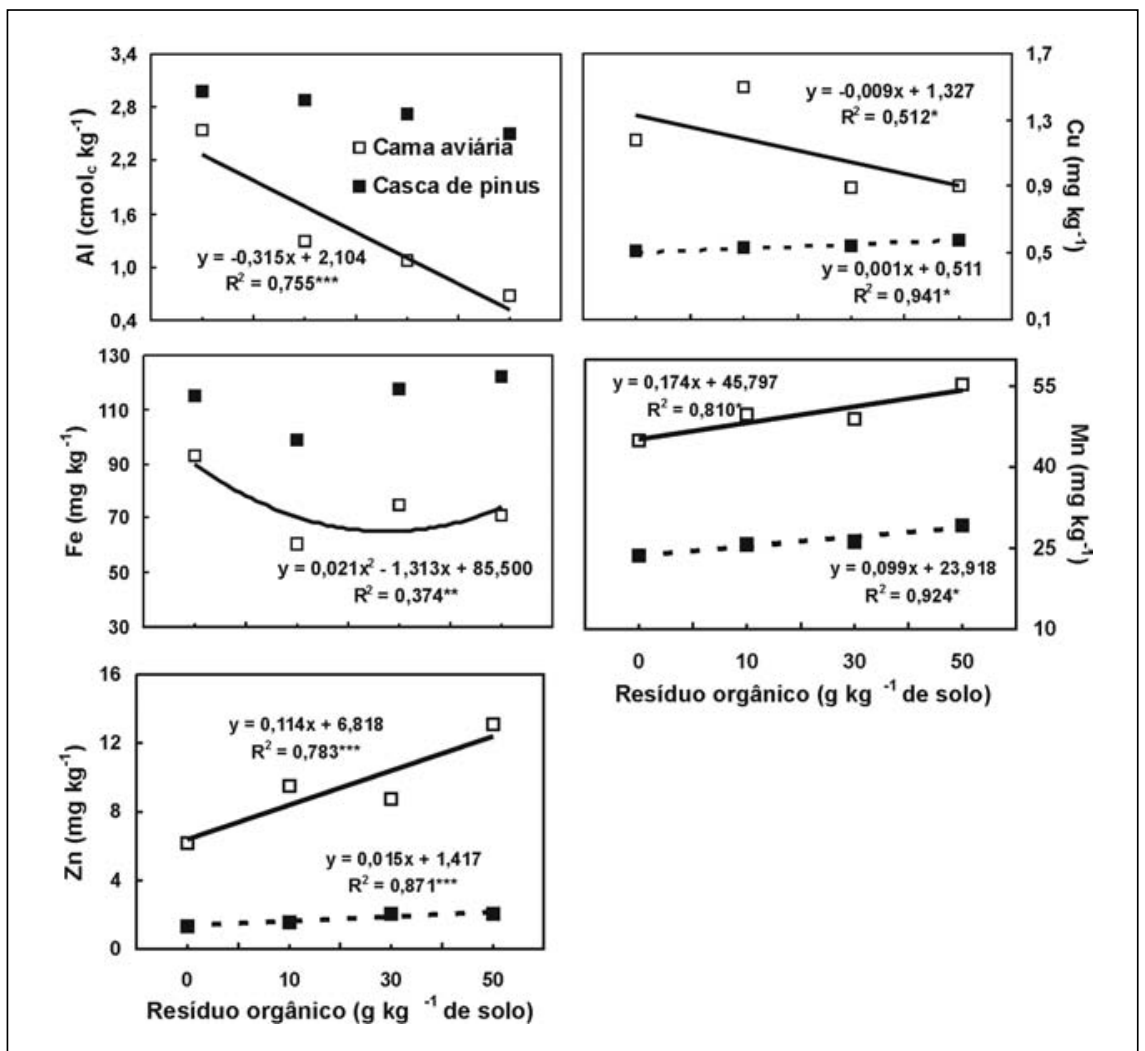

Figura 3. Avaliação residual de micronutrientes no solo, aos 150 dias após a aplicação de cama aviária ou casca de pinus, com quatro cultivos sucessivos de moranga e pepino nesse período $(*, * *$ e $* * *$ para regressão significativa a 5,1 e $0,1 \%$ de probabilidade, respectivamente). CAV/UDESC, 1999. 
de pepino 'Caipira' não foi alterado pela adição de cama aviária e casca de pinus (Tabela 1). A produtividade média foi mais de duas vezes superior em solos com cama aviária (Tabela 1) em relação aos demais tratamentos, tanto para a moranga 'Tetsukabuto' (14,49 $\left.\mathrm{t} \mathrm{ha}^{-1}\right)$ como para o pepino $\left(60,18\right.$ tha $\left.^{-1}\right)$. Scherer (1995) encontrou o nível ótimo para o rendimento de grãos de milho com aplicação de 6 e 12 t ha ${ }^{-1}$ de massa seca de cama aviária (equivalente a aproximadamente 8,6 e $17,1 \mathrm{t} \mathrm{ha}^{-1}$ de massa fresca de cama aviária) para um latossolo e um cambissolo, respectivamente.

O solo coletado no local de condução do experimento de campo 120 dias após a semeadura, e analisado para $\mathrm{pH}$, não apresentou diferenças entre os tratamentos controle e com casca de pinus, que tiveram valores de 5,5 e 5,6, respectivamente. No solo com incorporação de cama aviária o $\mathrm{pH}$ foi 6,6 . Isto mostra que a cama aviária, além de fonte de nutrientes, apresenta efeito alcalinizante, devido ao seu alto conteúdo de carbonatos e compostos nitrogenados (Gianello \& Ernani, 1983), aumentando a disponibilidade de nutrientes na fase solúvel do solo para as plantas, o que pode aumentar o potencial produtivo das plantas.

Os resultados obtidos mostram que a incorporação de cama aviária e, em menor intensidade a casca de pinus, melhoram as propriedades físicas e químicas do solo, favorecendo assim a emergência e o desenvolvimento inicial das plantas, o que pode ocasionar aumentos na produtividade de cucurbitáceas. A incorporação de cama aviária ao solo aumentou o $\mathrm{pH}$, reduziu os teores de Al trocável e aumentou a disponibilidade de macronutrientes $(\mathrm{N}$, $\mathrm{P}, \mathrm{K}$ e $\mathrm{Ca}$ ) e micronutrientes ( $\mathrm{Zn}$ e $\mathrm{Mn}$ ). A incorporação de casca de pinus aumentou a disponibilidade de micronutrientes ( $\mathrm{Zn}, \mathrm{Cu}$ e $\mathrm{Mn})$, mas ocasionou uma redução nos níveis de $\mathrm{N}$ no solo, possivelmente como resultado da atividade de organismos que atuam na decomposição do resíduo vegetal. Desta forma, em condições de campo, somente a incorporação de cama aviária, na dose de $30 \mathrm{~g} \mathrm{~kg}^{-1}$, apresentou efeitos substancias no aumento de rendimento de frutos em moranga 'Tetsukabuto' e pepino 'Caipira'.

\section{LITERATURA CITADA}

AMARANTE, C.V.T.; MACEDO, A.F Frutificação e crescimento de frutos em abóbora híbrida 'Tetsukabuto' tratada com alfanaftalenoacetato de sódio. Horticultura Brasileira, Brasília, v. 18, n. 3, p. 212-214, 2000.

BLUM, L.E.B. Benzaldehyde, kudzu (Pueraria lobata), velvetbean (Mucuna deeringiana), and pine bark for the management of Rhizoctonia solani and Sclerotium rolfsii. EUA: Auburn University. 1998. 230 p. (Tese doutorado).

BLUM, L.E.B.; KOTHE, D.M.; SIMMLER, A.O. Efeito da adição ao solo da casca de pinus e da cama de aviário na incidência de tombamento (Phytophthora capsici) em mudas de cucurbitáceas e pimentão. Fitopatologia Brasileira, Brasília, v. 24, suplemento, p. 268, 1999.

BLUM, L.E.B.; KOTHE, D.M.; SIMMLER, A.O.; PRADO, G.; AMARANTE, C.T.V. Manejo do tombamento em pepino pela adição ao solo de cama de aviário e casca de pinus. Revista de Ciências Agroveterinárias, Lages, v. 1, n. 1, p. 3340, 2002.

ERNANI, P.R. Necessidade da adição de nitrogênio para o milho em solo fertilizado com esterco de suínos, cama de aves e adubos minerais. Revista Brasileira de Ciência do Solo, Campinas, v. 8, n. 3, p. 313-317, 1984.

ERNANI, P.R.; GIANELLO, C. Diminuição do alumínio trocável do solo pela incorporação de esterco de bovinos e camas de aviário. Revista Brasileira de Ciência do Solo, Campinas, v. 7, n. 2, p. 161-165, 1983.

ERWIN, D.C.; BARTNICKI-GARCIA, S.; TSAO, P.H. Phytophthora - its biology, taxonomy, ecology, and pathology. APS Press, St. Paul, Minessota, 1983. 392 p.

GIANELLO, C.; ERNANI, P.R. Rendimento de matéria seca de milho e alterações na composição química do solo pela incorporação de quantidades crescentes de cama de frangos, em casa de vegetação. Revista Brasileira de Ciência do Solo, Campinas, v. 7, n. 3, p. 285-290, 1983.

HO, H.H. Synoptic keys to the species of Phytophthora. Mycologia, New York, v. 73, n. 4, p. 705-714, 1981.
HOITINK, H.A.J.; MADDEN, L.V.; BOEHM, M.J. Relationships among organic matter decomposition level, microbial species diversity, and soilborne disease severity. In: HALL, R. (ed.). Principles and practice of managing soilborne plant pathogens. APS Press, St. Paul, Minessota, 1996. p. 237-249.

KOKALIS-BURELLE, N.; RODRÍGUEZKÁBANA, R. Changes in populations of soil microorganisms, nematodes, and enzyme activity associated with application of powdered pine bark. Plant and Soil, v. 162, n. 2, p. 169-175, 1994.

KOTHE, D.M.; BLUM, L.E.B.; SIMMLER, A.O.; GUIMARÃES, L.S.; PRADO, G. Efeito da cama de aviário nos nutrientes e no $\mathrm{pH}$ do solo. In: IV JORNADAACADÊMICA E IX SEMINÁRIO CATARINENESE DE INICIAÇÃO CIENTÍFICA, Florianópolis, 1999. Anais. Florianópolis, UDESC, 1999, p. 79.

MACEDO, A.F.; GÜTTLER, G.; BLUM, L.E.B. Métodos de preparo do solo e de densidade de plantas no cultivo da abóbora 'Tetsukabuto'. Horticultura Brasileira, Brasília, v. 17, n. 3, p. 298, 1999.

MIELE, A.; MILAN, P.A. Composição mineral de cama de aviário de frangos de corte e sua utilização na adubação de vinhedos. Pesquisa Agropecuária Brasileira, Brasília, v. 18, n. 7, p. 729-733, 1983.

ODNEAL, M.B.; KAPS, M.L. Fresh and aged pine bark as soil amendments for establishment of highbush blueberry. HortScience, Alexandria, v. 25 , n. 10 , p. 1228-1229, 1990.

SCHERER, E.E. Avaliação do esterco de aves e da uréia como fontes de nitrogênio para a cultura do milho. Agropecuária Catarinense, Florianópolis, v. 8, n. 4, p. 15-18, 1995.

SIMMLER, A.O.; BLUM, L.E.B.; KOTHE, D.M.; GUIMARÃES, L.S.; PRADO, G. Efeito da casca de pinus no ter de nutrientes e no $\mathrm{pH}$ do solo. In: IV JORNADA ACADÊMICA E IX SEMINÁRIO CATARINENESE DE INICIAÇÃO CIENTÍFICA, Florianópolis, 1999. Anais. Florianópolis, UDESC, 1999, p. 80.

SNEH, B.; BURPEE, L.; OGOSHI, A. Identification of Rhizoctonia species. APS Press, St. Paul, Minessota, 1991. 135 p.

TEDESCO, M.J.; GIANELLO, C.; BISSANI, C.A.; BOHNEN, H.; VOLKWEISS, S.J. Análise de solo, plantas e outros materiais. $2^{\mathrm{a}}$ ed. Porto Alegre: Departamento de Solos, UFRGS, 1995. 174 p. (Boletim Técnico, 5).

TSAO, P.H.; OSTER, J.J. Relation of ammonia and nitrous acid to suppression of Phytophthora in soils amended with nitrogenous organic substances. Phytopathology, St. Paul, v. 71, n. 1, p. 53-59, 1981.

ZÁRATE, N.A.H.; VIEIRA, M.C.; CABEÇAS Jr., O. Produção de alface em função de doses e formas de aplicação de cama de aviário semi-decomposta. Horticultura Brasileira, Brasília, v. 15, n. 1, p. 65-67, 1997. 